Check for updates

Cite this: RSC Adv., 2019, 9, 23925

\title{
Electronic performance of printed PEDOT:PSS lines correlated to the physical and chemical properties of coated inkjet papers $\dagger$
}

\begin{abstract}
Viviane Forsberg, (D) *abc Jan Mašlík ${ }^{d}$ and Magnus Norgren (iD) a
PEDOT:PSS organic printed electronics chemical interactions with the ink-receiving layer (IRL) of monopolar inkjet paper substrates and coating color composition were evaluated through Raman spectroscopy mapping in $Z$ (depth) and (XY) direction, Fourier transform infrared spectroscopy (FTIR) and energy dispersive $X$-ray spectroscopy (EDS). Other evaluated properties of the IRLs were pore size distribution (PSD), surface roughness, ink de-wetting, surface energy and the impact of such characteristics on the electronics performance of the printed layers. Resin-coated inkjet papers were compared to a multilayer coated paper substrate that also contained an IRL but did not contain the plastic polyethylene (PE) resin layer. This substrate showed better electronic performance (i.e., lower sheet resistance), which we attributed to the inert coating composition, higher surface roughness and higher polarity of the surface which influenced the de-wetting of the ink. The novelty is that this substrate was rougher and with somewhat lower printing quality but with better electronic performance and the advantage of not having PE in their composite structure, which favors recycling.
\end{abstract}

Received 20th May 2019

Accepted 22nd July 2019

DOI: 10.1039/c9ra03801a

rsc.li/rsc-advances

processes to produce conducting polymers using $\mathrm{FeCl}_{3}$ or $\mathrm{H}_{2} \mathrm{O}_{2}$

\section{Introduction}

Three scientists, Shirakawa, MacDiarmid and Heeger, presented their breakthrough research on conducting polyacetylene doped with halogens in 1977.' Nowadays, polyacetylene is known as a prototype conducting polymer and can be $\mathrm{p}$ - and n-doped chemically or electrochemically. ${ }^{2}$ This discovery was recognized with the Chemistry Nobel Prize in $2000 .^{3}$ Studies of a number of different conducting polymers were an inevitable development after their discovery. ${ }^{4,5}$ Watersoluble conducting co-polymers poly(3,4-ethylenedioxythiophene)-poly(styrene sulfonic acid) (PEDOT:PSS) discovery occured in $1995,{ }^{6}$ and a number of other studies around this polymer emerged thereafter. ${ }^{7-9}$

PEDOT is insoluble, but when PSS, a water-soluble polyelectrolyte is used as a counter ion, the system is stabilized. ${ }^{\mathbf{1 0}}$ Today, all printed transistor circuits are possible using only organic polymers ${ }^{\mathbf{1 1}}$ and more recently two-dimensional materials. $^{\mathbf{1 2 , 1 3}}$ Vapor-phase polymerization is one of the available

${ }^{a}$ Mid Sweden University, FSCN, Surface and Colloid Engineering, Holmgatan 10, SE-851 70, Sundsvall, Sweden. E-mail: viviane.forsberg@miun.se

${ }^{b}$ KTH Royal Institute of Technology, Department of Fiber and Polymer Technology, Biocomposites Division, Teknikringen 56, SE-100 44, Stockholm, Sweden. E-mail: vivforsb@kth.se

${ }^{c}$ Wallenberg Wood Science Centre, Teknikringen 56, SE-100 44, Stockholm, Sweden ${ }^{d}$ Tomas Bata University in Zlin, Centre of Polymer Systems, Trida Tomase Bati 5678, CZ-760 01, Zlin, Czech Republic

$\dagger$ Electronic supplementary information (ESI) available. See DOI: 10.1039/c9ra03801a as oxidizing agents. ${ }^{\mathbf{1 0}}$ The great advantage of solutionprocessable polymers is that they can easily be printed with commercially available inkjet printers with minimal usage of material and achieve conductive path lines with very few printing passes. ${ }^{\mathbf{1 4}}$

To date, there are many efforts to replace materials that are becoming less readily available, which impacts commercial costs such as indium tin oxide (ITO) ${ }^{\mathbf{1 5}}$ with materials that can be used in flexible displays. A telephone screen that does not break will certainly appear more appealing than the technology available nowadays.

Thin-film transistors (TFTs) of layered materials using graphene or MXenes as conductors, phosphorene, molybdenum disulfide or other layered transition metal dichalcogenides as semiconductors and boron nitride or silicates as insulators have been reported, ${ }^{12,13,16,17}$ and although they perform better than organic electronics in terms of electron mobility (i.e., $>10 \mathrm{~cm}^{2}$ $\mathrm{V}^{-1} \mathrm{~s}^{-1}$ ) and have remarkable mechanical and electronic properties due to quantum confinement when the layers of the materials are exfoliated, ${ }^{\mathbf{1 8 - 2 2}}$ there are still limitations to using these materials in flexible devices. The high intrinsic mobility ${ }^{23}$ also demands additional engineering steps at the junctions to improve mobility. ${ }^{22}$

Organic electronics, on the other hand, have clear advantages compared to layered materials for low power electronics. Flexible and with high conductivity in the order of $4.6 \mathrm{~S} \mathrm{~cm}^{-1}$ when doped with PSS into a conductive state, ${ }^{24,25}$ PEDOT is one of the most used conductive polymers nowadays. PEDOT has 
both high electronic and high ionic conductivity. The fact that it has high electrical conductivity and low thermal conductivity makes it a potential candidate for thermoelectric generators, ${ }^{26}$ which can be quite useful for self-powered sensors.

The substrates used for printed electronics have primarily been plastics, but the alarming consequences of the unsustainable use of these materials necessitate action particularly highlighted by the Sustainable Development Goals adopted by the United Nations for 2030. ${ }^{27}$ Biodegradable electronics ${ }^{28}$ could help to reduce the impact of discarded electronics waste that has become a problem causing pollution of soil and water especially when the costs for electronics are so low. ${ }^{25}$

With the advances of the Internet of Things (IoT) becoming more and more a reality and with embedded automation and smart systems integration, trillions of sensors will be needed to enable artificial intelligence. ${ }^{29}$ With this, the need for devices that are self-powered and cheap has also become a drive to develop technologies to enable the use of sustainable, flexible substrates.

The use of paper as a substrate for this purpose has numerous advantages because paper is a cheap commodity material and the paper industry is capable of supplying enough surface area for printed electronics in a month, which would take the silicon-based industries a year to achieve. ${ }^{30}$ Some paper grades may have higher surface roughness than plastics like PE. This roughness may be reduced with surface coating and calendering. Ihalainen et $a l .{ }^{31}$ presented a study of the influence of paper roughness on the electrical performance of printed wires using silver nano-particles and organic polymer (i.e., polyaniline) inkjet inks and found a linear correlation between resistance and short length roughness of the print substrates.

Porous IRLs are thick layers (i.e., $30<h<50 \mu \mathrm{m}),{ }^{32}$ and only a very small swelling of the binders contributes to the total ink absorption, and all of the ink must be absorbed by the pores formed between the pigments and within the pigments. Substrates contained the PE layer were designed to have the thick IRL to absorb all the ink solvent while ensuring good wetting and printing quality for inkjet papers. The PE layer also reduces the roughness considerably ${ }^{31}$ as it will be discussed shortly.

For inkjet printing, according to Kettle et al., ${ }^{33}$ there are seven interaction phenomena that coexist during the inkjet ink absorption process. Wetting occurs as soon as the droplet hits the paper surface. At the same time, the capillary forces start to act, forcing the ink to penetrate the IRL; this happens at around $0.1 \mathrm{~ms}$ after the droplet has contacted the surface. ${ }^{34,35}$ After a few milliseconds, the separation of the ink components starts taking place and the capillary penetration continues strongly. Adsorption increases after $1 \mathrm{~s}$. Diffusion starts at the capillary's ink penetration and increases with time when the ink has penetrated deeper into the coating structure. Finally, the last two phenomena that occur during ink absorption after the inkjet printing process are polymerization and drying. Polymerization, for inks which have the ability to polymerize, takes at least $100 \mathrm{~s}$ to start occurring, and the final drying rate of the ink can be in the range of hours. ${ }^{33}$
Understanding high-performance paper substrates, especially the coating layers (CLs) of the IRLs of these substrates regarding the porous structure, ${ }^{33}$ coating color composition, roughness, ${ }^{\mathbf{3 1}, 36}$ the mechanisms of ink penetration, ${ }^{33}$ ink de-wetting ${ }^{37,38}$ and the impact of such characteristics on the electronics performance of the substrates, could provide a direction for product development of grades to enable better electronics performance, especially for printing with organic conductive inks. With this in mind, we investigated the effects of different substrates on printability and electrical resistance.

Six substrates were carefully characterized and subjected to inkjet printing using a water-based ink containing PEDOT:PSS. Ink distribution was characterized using Raman spectroscopy and SEM, considering de-wetting phenomena. Effects from ink distribution on electrical resistance of the printed lines were analyzed. We evaluated that even though rough substrates lead to poorer printability, the electrical resistance is lower because the roughness will create areas with thicker ink layers than others, lowering the sheet resistance in some places. The printability could be improved by surface treatment of such substrates with silanization. ${ }^{39,40}$

\section{Experimental}

\section{Inkjet printing of the conductive lines}

The substrates were printed using a commercially available PEDOT:PSS water-based ink with $0.8 \mathrm{wt} \%$ (Orgacon IJ 1005, Sigma Aldrich), surface tension of $24 \mathrm{mN} \mathrm{m}^{-1}$ (Krüss, K6), and $\mathrm{pH}$ of 1.5-2.5. A Dimatix 2831 printer and Dimatix 11610 cartridges with $10 \mathrm{pL}$ drop volume were used to print the contact lines. The template was printed using $20 \mu \mathrm{m}$ drop spacing, which corresponds to a resolution of $1270 \mathrm{dpi}$. The conversion of centimeter to pixel can be done using the factor $x R / 2.54$, where $x$ is the length in centimeter, $R$ the resolution in dots per inch and 2.54 is a conversion factor, the thickness of the printed lines in micrometer will be described in the text.

The template used for the electronic analyses with 2-probes was printed using four nozzles and one printing pass. The waveform used was the one supplied by the manufacturer for distilled water with no alterations. For the Raman measurements and 4-probe sheet resistance analyses, the 20 pixel lines of the template were printed three-times and the measurements were done on the contacts areas for the Raman and on the lines for the sheet resistance. We used 1 nozzle to print these patterns.

\section{Estimation of the surface roughness of the substrates}

We evaluated the surface roughness through AFM measurements on a $50 \mu \mathrm{m}^{2}$ area of the substrates using a Dimension ICON (Bruker) instrument working in a PeakForce with ScanAsyst-Air probe without a controlled environment. The surface roughness was calculated using the software NanoScope Analysis. 


\section{SEM analyses of the morphology of the pores in the IRLS}

We obtained SEM images (TESCAN MAIA3, Triglav) of the top surface of the substrates at $39500 \times$ magnification, acquired at $2 \mathrm{keV}$ at the working distance of $\approx 7 \mathrm{~mm}$ with a SE detector in ultra high-resolution mode (UHR). The morphology tool of the software was employed to estimate PSD through imaging processing. Samples were cut into small squares and attached to an aluminum stub using double-sided coated carbon tape. Silver conductive ink was applied at the edges of the sample, once dried, they were coated with $5 \mathrm{~nm}$ iridium (Q150T ES, Quorum) to avoid electrostatic charging of the samples.

\section{Coating composition analyses through EDS}

Cross-section SEM images (TESCAN MAIA3, Triglav) of the substrates embedded in slow-curing transparent epoxy resin (Epofix Kit, Struers) were taken to perform the EDS analyses.

Initially all samples were attached into an aluminum spring and the resin deposited into a Teflon container using a vacuum chamber. The spring was removed by pulling it, and the samples polished. The embedded samples were polished following a protocol with a sequence of sand papers (\#320, \#500, \#1200, \#4000, Largo $6 \mu \mathrm{m}$, Dur $3 \mu \mathrm{m}$ and Nap $1 \mu \mathrm{m}$, Struers). We ran the equipment for $\approx 4$ min using water for the coarser grades (\#320 and \#500) and for $\approx 2 \mathrm{~min}$ for the finer ones using DP lubricant (TegraPol-21 equipped with a Tegra Doser-5, Struers).

The embedded samples attached to the aluminum stub are illustrated in Fig. 1. The sample was coated with $5 \mathrm{~nm}$ chromium and accessed right after to avoid the oxidation of the coating. Images were accessed using backscattered electron detector (BSE) in analysis mode at $20 \mathrm{keV}$. The EDS detector (Oxford Instruments accessory X-Max 50) was coupled with the SEM equipment, and the Aztec software was used for data acquisition and analyses.

\section{Coating composition analyses through FTIR}

FTIR (Nicolet 6700 FT-IR) spectra of the substrates were taken using the instrument's attenuated total reflectance (ATR) mode. Before acquisition of spectra, we purged the instrument for $30 \mathrm{~min}$ with nitrogen to attenuate the spectral contribution from atmospheric water and carbon dioxide. The spectra were acquired with 64 scans and resolution 2 (i.e., $0.964 \mathrm{~cm}^{-1}$ ).

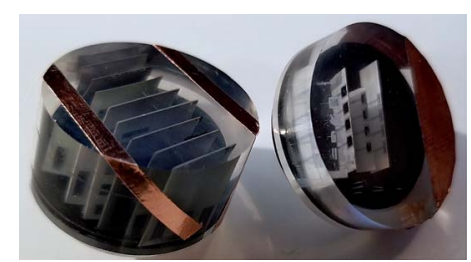

Fig. 1 Photograph of the embedded samples in resin for the SEM-EDS cross section analyses.

\section{Contact angle measurements to estimate surface energy} parameters

Contact angle measurements to determine the surface energy on the substrates were performed using the Advex instrument. Measurements were taken at $23{ }^{\circ} \mathrm{C}$ room temperature. We used $3 \mu \mathrm{L}$ of the liquids, and the images were taken a few seconds after drop contact to the surface until the drop geometry was stabilized. Each measurement was repeated 5 times.

\section{Ink distribution and ink-substrate chemical interactions}

We used Raman spectroscopy (Horiba Xplora Plus) to evaluate the chemical interactions ink-substrate in the $Y Z$ direction and to map the surface in the $X Y$ direction. Both analyses were done in the $X Y Z$ direction to determine the focus point; the differences in the measurements were the number of data points and increment. These measurements were performed in confocal mode at $100 \mu \mathrm{m}$, using a $100 \times$ objective (Olympus MPlan) with numerical aperture equal to $\mathrm{NA}=0.90$. The excitation wavelength of the laser was $532 \mathrm{~nm}$, with a $600 \mathrm{~nm}$ groove, a slit width opening of $100 \mu \mathrm{m}$ and $1 \%$ laser power (i.e., $2.5 \mathrm{~mW}$ ) to avoid overheating of the substrates. Acquisition time was $20 \mathrm{~s}$, and there were 3 accumulations (i.e., average of three spectra for each point). The spectral pixel resolution (i.e., the sampling interval of the spectrum) was $0.4 \mathrm{~cm}^{-1}$.

We also performed FTIR on the top of the printed lines and the substrates to evaluate the chemical interactions between the substrate and the ink. This was done on the outermost surface of the ink. The Raman spectroscopy analyses complemented these analyses in depth into the sample in $Z$ direction.

\section{Electrical properties of printed lines}

The electrical properties of the printed lines were evaluated for different line thicknesses and sintering temperatures using a bench multimeter (34410A 6.5, Agilent) with two probes but also performed analyses of sheet resistance using a four-probe measurement device unit type $\mathrm{G}$, tip $R 100 \mu \mathrm{m}$, force $100 \mathrm{~g}$. The probes were equidistant $0.635 \mathrm{~mm}$ (Jandel), these were coupled with a bench multimeter (2611A Keithley).

\section{Results and discussion}

This section is divided into three parts. Part one refers to the physical and chemical characterization of the surface of the substrates S1 to S6 in terms of PSD, surface roughness, the composition of the CLs in the IRLs of the substrates and the contact angle measurements to estimate the surface energy. Part two is related to the printed PEDOT:PSS lines, the ink distribution (de-wetting) on the surface of the substrates and the analyses of ink-substrate chemical interactions. Part three is related to the electrical properties of the printed lines and how the results from Part one and Part two help us to answer the research question regarding the impact on the ionic/electronic performance of the PEDOT:PSS printed lines depending on the substrate chemical and physical characteristics. We end this section with some references to electronics applications performed on some of the substrates analyzed in this study. A 
summary of the results for the characterization of the substrates is indicated in Table 1.

\section{Part 1: physical and chemical surface characterization of the substrates}

To access the chemical composition of the CLs, we used two methods: FTIR and EDS. These methods complemented one another. The resolution limitation of the different techniques used in this study are explained in the ESI. $\dagger$

EDS analyses of the CLS of the IRL. The analyses of the substrates using FTIR gave mostly information about the outermost layers of the substrates. The electron images (EIs) with the multiple and single CLs that are highlighted in yellow in Fig. 3 indicate the regions where the EDS area scan was performed on each CL of the cross-section images. The cross section image taken with the BSE indicate the CLs and the other layers of the composite substrate in better resolution (see Fig. 2). Three of the substrates contained more than one CL in their IRLs; that is the case for S1, S5 and S6, being those the ones that we magnified the IRL for better visualization of the CLs in Fig. 2. Part of the crosssection image contained the resin that the substrates were embedded during sample preparation (see Fig. 1) and the PE layers on the top and bottom of the base paper (BP).

S1 was provided by Åbo Akademi and contain 3 CLs. It was produced in laboratory scale and was also calendered. S2 to S6 are resin-coated substrates all containing an extruded pigmented PE layer on the top and a non-pigmented PE on the back of the BP. On the top of the PE layer there is the IRL containing one CL for S2, S3 and S4 and two CLs for S5 and S6.

The total surface mapping was performed in the entire crosssection images that are illustrated in color in Fig. 3 on top of the EI. The atomic composition in percentage and the spectra of the CLs measured for the area scans are presented in Fig. 4, the thickness of the layers are also indicated. For the surface mapping of the cross-section these results are presented in the ESI Fig. S1. $\dagger$

Elemental Si and Al were identified in the EDS analyses which is in agreement with the FTIR analyses for boehmite $[\mathrm{AlO}(\mathrm{OH})]$ and silica $\left(\mathrm{SiO}_{2}\right)$. Some substrates contained both pigments in their IRL coating composition. For S1 we note a 3.4 $\mu \mathrm{m}$ silica layer in CL1 constituted of mainly Si (i.e., 3.7\%) followed by a $17 \mu \mathrm{m}$ CL2 constituted of highly oriented platy pigments containing alumina and silica at slightly the same

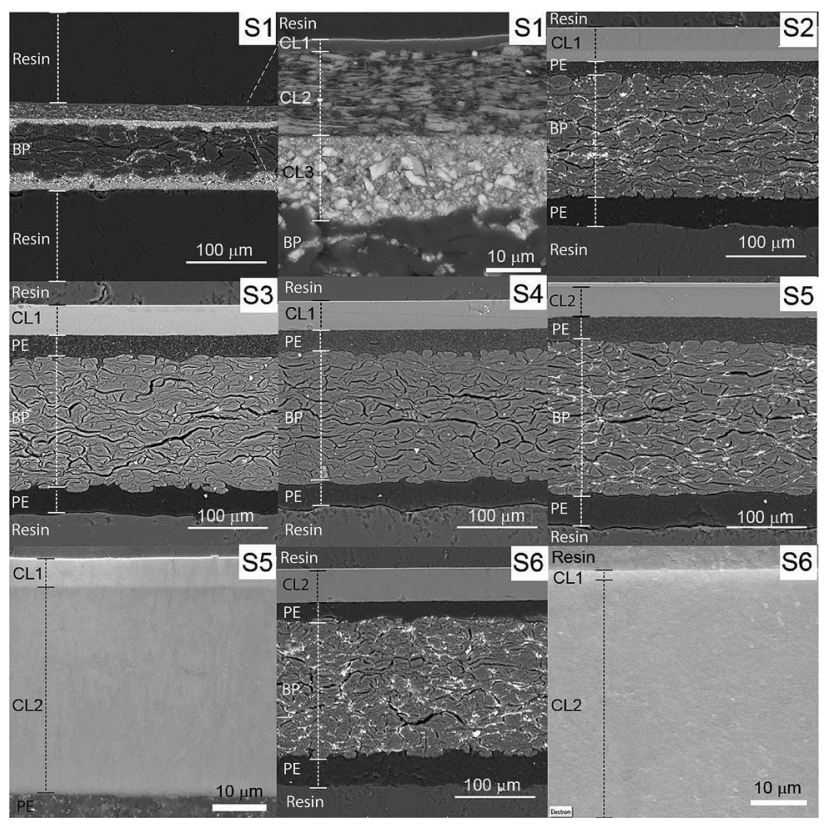

Fig. 2 Cross-section SEM images of the substrates accessed at $20 \mathrm{keV}$ at working distance $\approx 7 \mathrm{~mm}$ in UHR mode using a BSE to improve contrast. Where the scale is $10 \mu \mathrm{m}$, the images were taken at a viewfield of $50 \mu \mathrm{m}$ and acquired in analysis mode using a SE detector. The CLs are indicated in the image as well as the PE and BP composite layers. Resin refers to the embedded material of the sample. A thin gold layer $4 \mathrm{~nm}$ was sputtered on the top of the sample to help distinguish between the $C L$ and the resin interface.

atomic percentage proportion (i.e., 6.1 and 6.3\% for $\mathrm{Si}$ and $\mathrm{Al}$ respectively), and a $9.8 \mu \mathrm{m}$ CL3 containing mainly Ca (i.e., 15\%), which we attribute to the presence of $\mathrm{CaCO}_{3}$ with broad particle size distribution. S2, S3 and S4, contain only one pigment in the CL1 (i.e., elemental Al in S2 and Si for S3 and S4).

The analyses of the accuracy of the EDS measurement was done through the evaluation of the background. The background is the curved baseline at the bottom of the spectra (see Fig. 4). A rule of thumb is that the data are detectable if 3 times the square root of the peak height is higher than the background. If this condition is not fulfilled, the data are not detectable and could appear as noise. When evaluating the surface mapping shown in Fig. 3, there are some regions colored outside the IRL region which we know is due to noise.

Table 1 Thickness of each layer ( $L$ ) of the composite substrate. Note that S1 does not contain a PE layer so L1, L2 and L3 correspond to the CL1, $\mathrm{CL} 2$ and $\mathrm{CL3}$. For the other substrates the layer before the BP is the PE layer. S2 to S4 contain only one CL. Composition of the CLs of the IRLs was estimated through EDS and FTIR measurements. The RMS roughness $\left(S_{\mathrm{q}}\right)$ was estimated through AFM measurements. The total surface energy of the substrates $\left(\gamma_{S}\right)$ was estimated by contact angle measurements

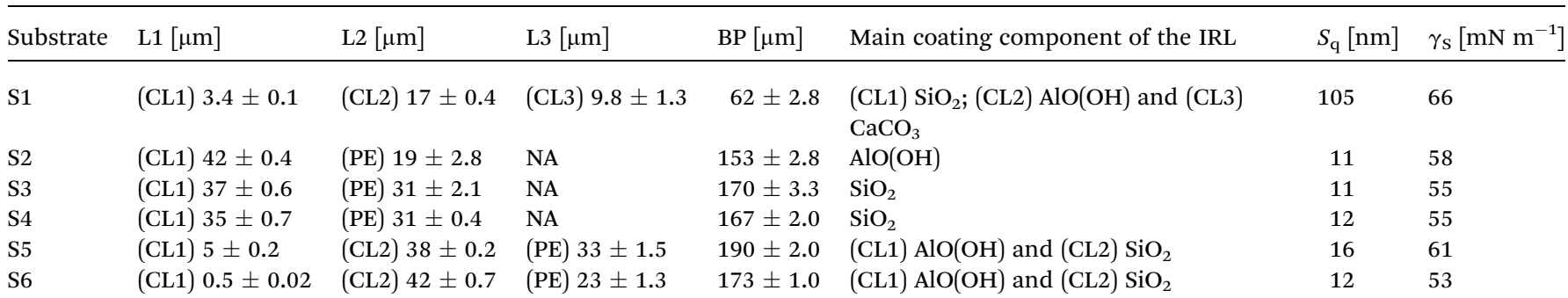



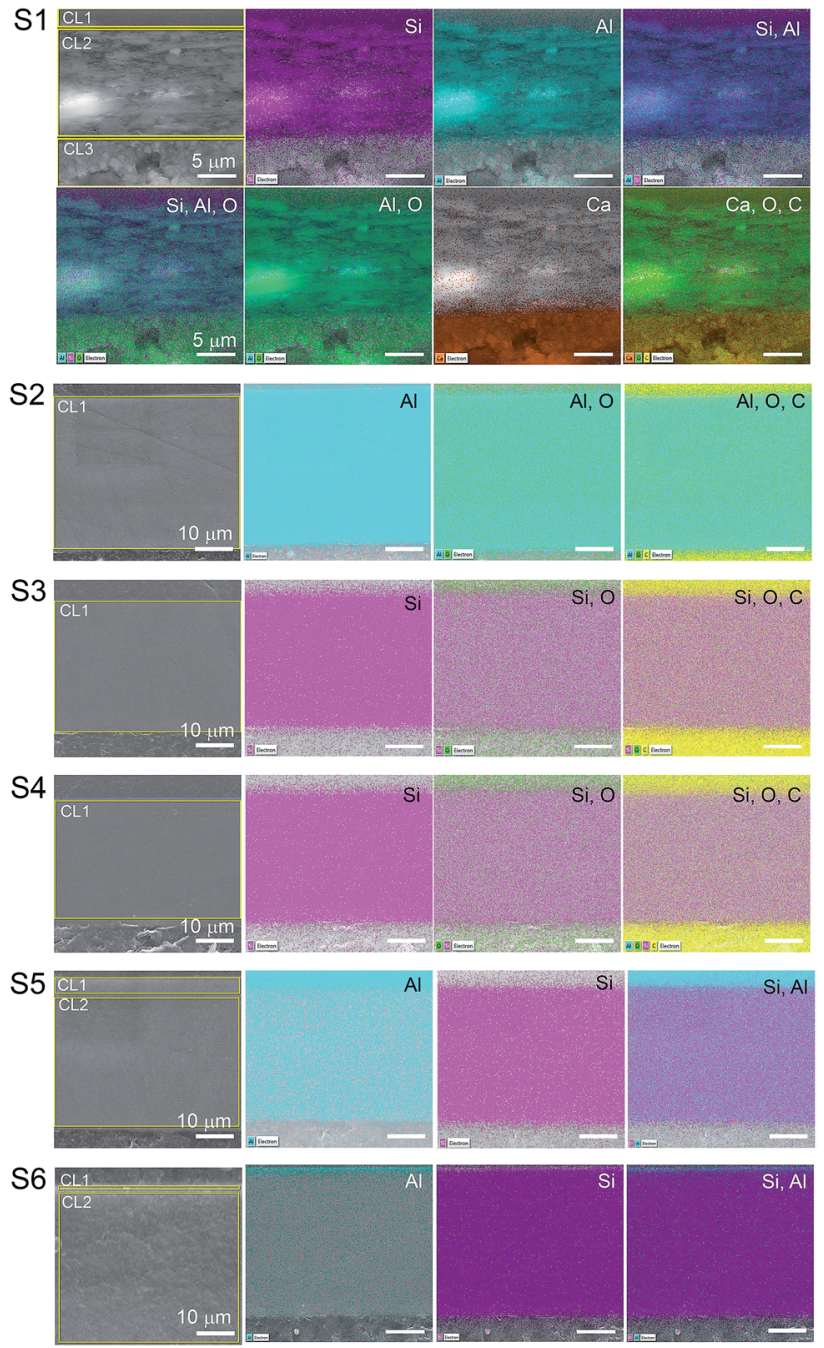

Fig. 3 EDS mapping of the cross-section surfaces of the substrates. The areas surrounded by yellow in the El were the regions used for the area scan. The scales of the images are the same as that of the first image on the line. The elements identified in the mapping are indicated in the image as silicon (Si), aluminum (Al), oxygen (O), calcium (Ca) and carbon (C). The elemental spectra and atomic percentage of the mapping is presented in the ESI.†

The principal X-ray emission lines are indicated in Table S1 in the ESI. $\dagger$

FTIR analyses of the CLs of the IRLs. The spectra containing the absorption bands and assigned vibrations on each substrate acquired using ATR-FTIR are presented in Fig. 5. Briefly, we identified that the binder used in all substrates was polyvinyl alcohol (PVOH). Substrates S2, S5 and S6 contain boehmite alumina $\mathrm{AlO}(\mathrm{OH})$. Amorphous silica $\left(\mathrm{SiO}_{2}\right)$ is present on the substrates $\mathrm{S} 1, \mathrm{~S} 3, \mathrm{~S} 4$ and $\mathrm{S} 6$. In $\mathrm{S} 6$, there is both $\mathrm{AlO}(\mathrm{OH})$ and $\mathrm{SiO}_{2}$, here the EDS analyses was complementary because of the thin alumina layer for CL1; which would be detected by FTIR together with the CL2 due to the small thickness of CL1 (i.e., $t=0.5 \mu \mathrm{m}$ ). See the explanation at the ESI $\dagger$ for the limits of detection of this technique.

The analyses of the spectra indicated the appearance of symmetric and asymmetric stretching IR vibrations in $\mathrm{OH}$
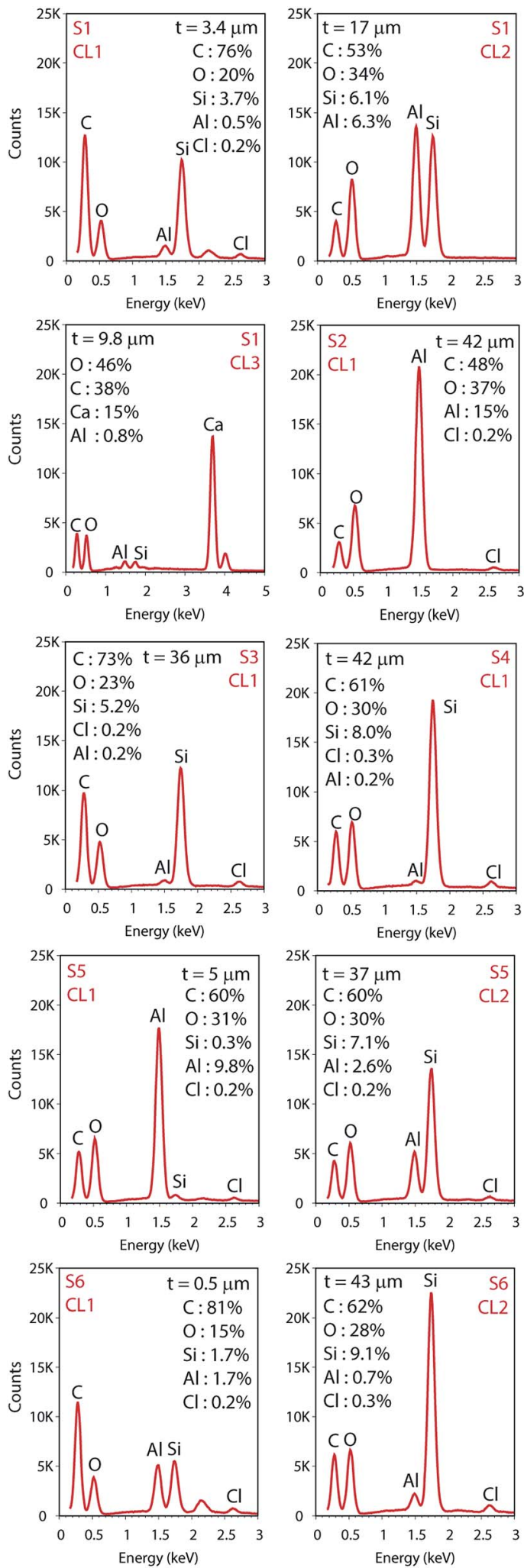

Fig. 4 Area scan spectra for the coated IRLs. The top coat (CL1), second (CL2) and third (CL3) coated layers are indicated. The thickness of the layer $(t)$ is indicated in $\mu \mathrm{m}$ and the elemental-atomic percentage of the main components is indicated.

groups ${ }^{41}$ at 3098 and $3286 \mathrm{~cm}^{-1}$ for the substrates S2, S5 and S6 indicating the presence of $\mathrm{AlO}(\mathrm{OH})$ in their IRLs. There are 6 fundamental modes (FMs) of vibration in a 4-atom nonlinear 


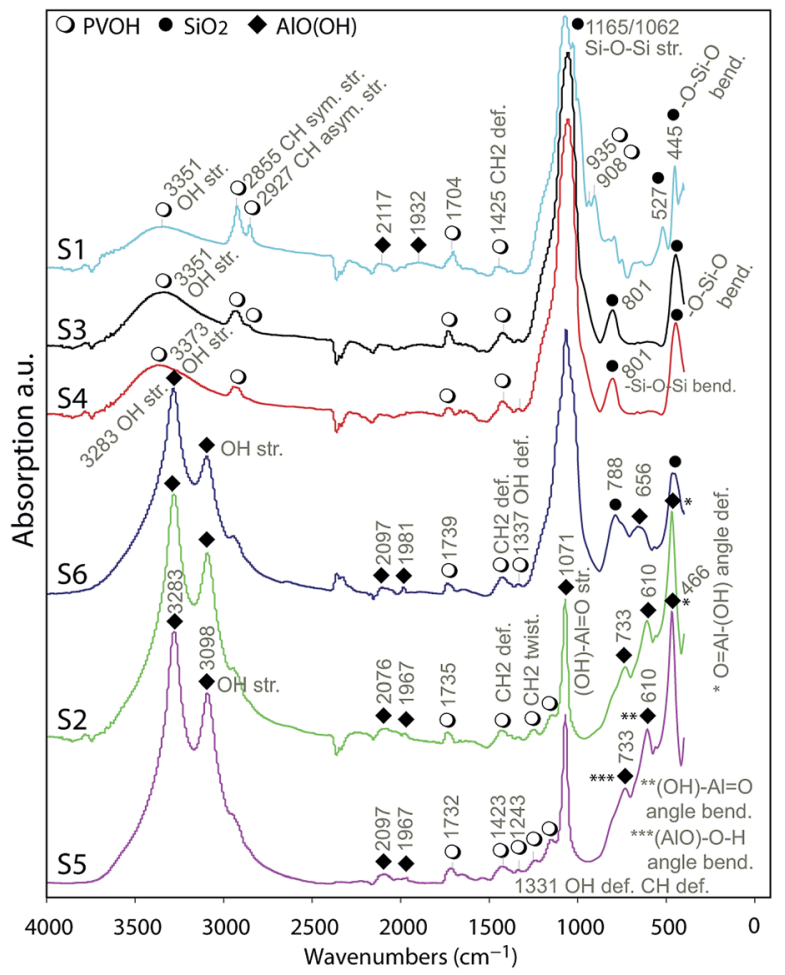

Fig. 5 FTIR analyses on the surface of the substrates indicating the presence of $\mathrm{AlO}(\mathrm{OH})$, silica and $\mathrm{PVOH}$ referred by icons in the legend.

molecule as $\mathrm{AlO}(\mathrm{OH})$; these are well illustrated in the literature. ${ }^{42}$ Assuming AlO as a single-point mass the $\mathrm{OH}$ group's IR vibrations can be described as $\mathrm{OH}$ group stretching, (AlO)-O-H angle bending and (AlO)-O- $\mathrm{H}$ deformation.

The other three FMs of vibration can be described as $(\mathrm{OH})-$ $\mathrm{Al}=\mathrm{O}$ symmetric bond stretching, $(\mathrm{OH})-\mathrm{Al}=\mathrm{O}$ angle bending and $(\mathrm{OH})-\mathrm{Al}=\mathrm{O}$ asymmetric bond stretching. ${ }^{42}$ Well-resolved absorbance bands were observed in the region from 400 to $1200 \mathrm{~cm}^{-1}$. Taking, for example, S2, these bands were at 466, $610,733,1071$ and $1147 \mathrm{~cm}^{-1}$. At $1071 \mathrm{~cm}^{-1}$, a sharp and strong band is assigned to the $(\mathrm{OH})-\mathrm{Al}=\mathrm{O}$ asymmetric stretching vibration, and the small shoulder at $1147 \mathrm{~cm}^{-1}$ is related to the $\mathrm{O}-\mathrm{H}$ bending. The (AlO)-O-H angle bending is indicated by the $733 \mathrm{~cm}^{-1}$ band and the $(\mathrm{OH})-\mathrm{Al}=\mathrm{O}$ angle bending is attributed to the band at $610 \mathrm{~cm}^{-1}$. The sharp band at $466 \mathrm{~cm}^{-1}$ is attributed to the angle deformation (wagging) of $\mathrm{O}=\mathrm{Al}-(\mathrm{OH})$. The bands in the region 1500 to $2500 \mathrm{~cm}^{-1}$ are relatively weaker compared to those in the other regions. The broader peak at $1165 \mathrm{~cm}^{-1}$ for S6 indicate the presence of silica in the IRL as it was discussed previously on the EDS analyses.

Taking, for example, S1, S3 and S4, the assignments of the absorption bands at $445 \mathrm{~cm}^{-1}, 801 \mathrm{~cm}^{-1}, 1062 \mathrm{~cm}^{-1}$ and $1140 \mathrm{~cm}^{-1}$ are well-known assignments to the vibrations of the tetrahedral $-\mathrm{SiO}_{4}$ groups. ${ }^{43,44}$ The two components at $1165 \mathrm{~cm}^{-1}$ and $1062 \mathrm{~cm}^{-1}$ are due to the 3 -fold degenerated $\mathrm{Si}-\mathrm{O}-\mathrm{Si}$ asymmetrical stretching frequencies of the tetrahedral $-\mathrm{SiO}_{4}$ structural unit. The absorption band around $801 \mathrm{~cm}^{-1}$ is due to -Si-O-Si bending modes, while the one at $445 \mathrm{~cm}^{-1}$ is due to -O-Si-O bending. ${ }^{45}$ The bands around $3351 \mathrm{~cm}^{-1}$ are due to
-OH stretching, ${ }^{44}$ while the bands at $2855 \mathrm{~cm}^{-1}$ and $2927 \mathrm{~cm}^{-1}$ are due to $\mathrm{CH}$ symmetrical and asymmetrical stretching related to the vibrations of the PVOH molecule.

Morphology of the pores and PSD. The composition of the coating colors include not only pigments but also binders and other additives. Natural and synthetic polymeric binders are often present in the composition of IRLs of the paper substrates. Observing the images collected with the SEM of the surface of the substrates illustrated in Fig. 6, there are regions occupied by the pores and regions occupied by the pigment/binders. These regions will have different brightness, and by exploring this feature, an algorithm in the TESCAN software enables the estimation of the morphology of the pores. The brightness difference can be used to define a threshold between the porous and nonporous structures ${ }^{46}$ and in this way estimate the PSD.

The IUPAC system classifies pores according to the diameter $(D)$ as follows: micropores, $<2 \mathrm{~nm}$; mesopores, $2<D<50 \mathrm{~nm}$; and macropores $>50 \mathrm{~nm} \cdot{ }^{47}$ In Fig. $7 \mathrm{~A}$ the analyzed pores are highlighted in yellow. The length and width of the pores are presented in the histograms in Fig. 7B and C respectively. Most of the porous IRLs have pores in the macropores range. S1 and S3 have broader PSD. S3 is the most porous substrate with a significantly higher number of pores compared to the other substrates. The main differences between these two substrates would be the thickness of each CL, the absence of the PE layer for $\mathrm{S} 1$ and the composition of the CL that was discussed in the previous section.

It is common to refer to the Lucas-Washburn ${ }^{48}$ equation (eqn (1)) to discuss penetration of fluids into porous media.
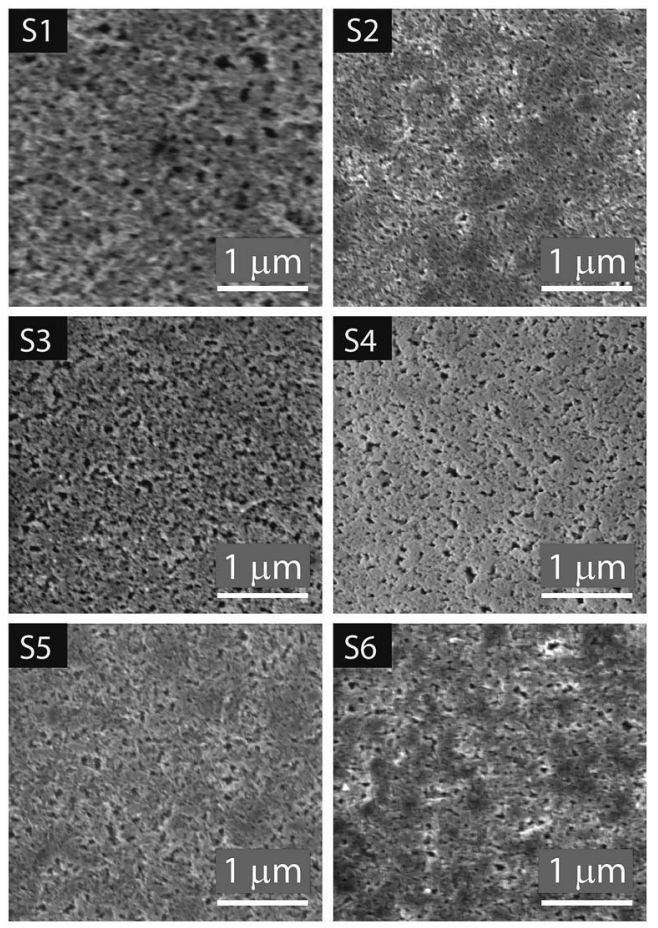

Fig. 6 SEM images of the top surface of the substrates at $39500 \times$ magnification with the scale indicating $1 \mu \mathrm{m}$, view field $3.5 \mu \mathrm{m}$ accessed at 2 ke $\mathrm{V}$. 


$$
L=\left(\frac{D \cos \theta \gamma t}{2 \eta}\right)^{1 / 2}
$$

In this equation, the length $(L)$ of the ink penetration is directly proportional to the square root of the pore diameter $(D)$, where $\gamma$ is the surface tension of the liquid, $\eta$ is the dynamic viscosity, $t$ is time of the fluid penetration in seconds and $\theta$ is the contact angle. This means the bigger the pores, the faster

A
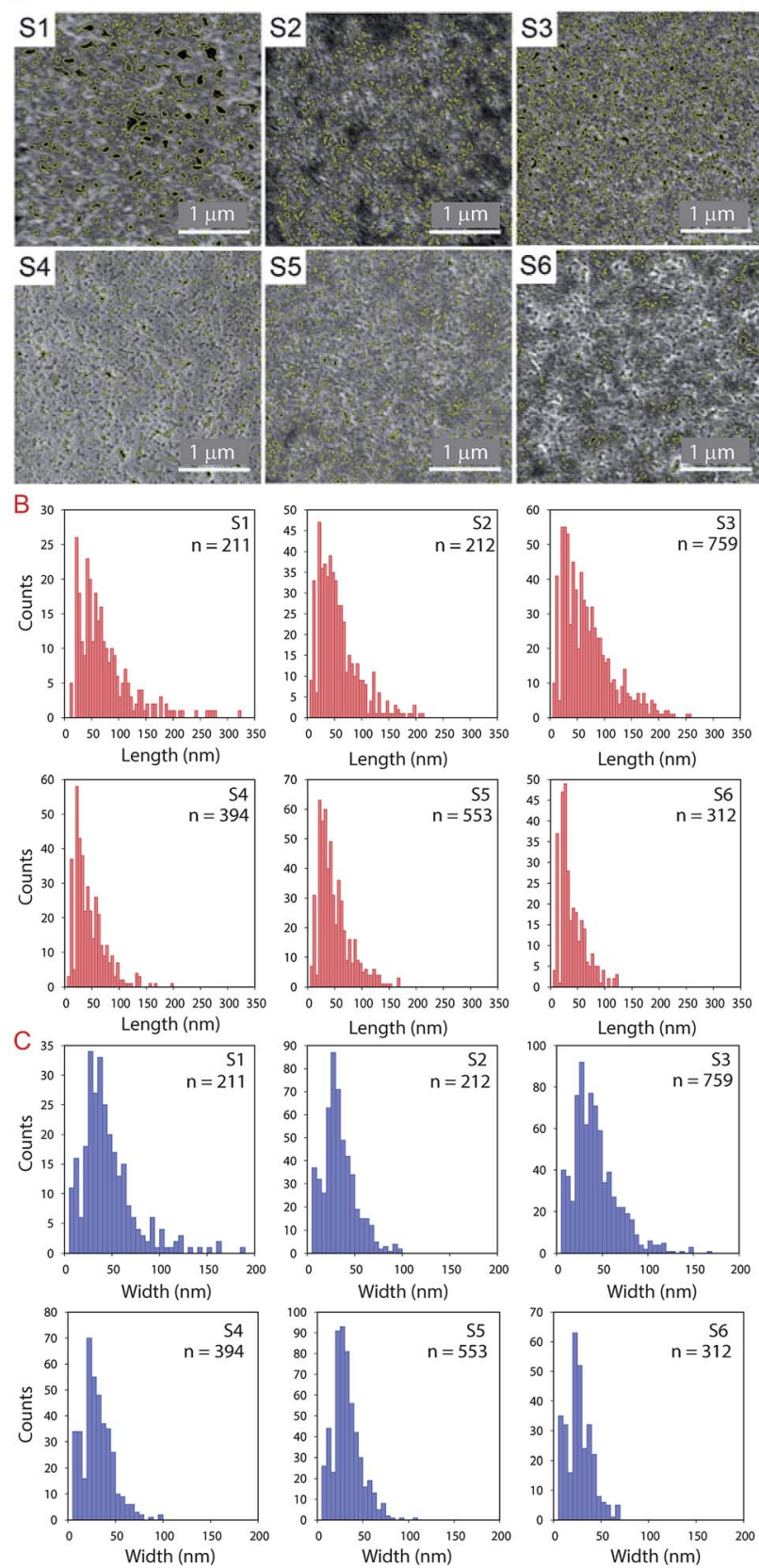

Fig. 7 PSD analyses by processing SEM images (A) indication of the analyzed pores highlighted in yellow on the top of the substrates. The analyses were done using the image processing tool morphology of the software from the SEM instrument. (B) Histograms of the PSD after morphology analyses considering the length and (C) the width of the pores; $n$ indicates the number of pores analyzed. the ink solvent penetration. However, the pores should not be bigger than the ink particles because it is the ink solvent's fast penetration that is important, and as little as possible of the pigment to penetrating the IRL is ideal. The bigger pores in S1 contribute to a faster ink absorption and penetration which cause poor printability but the fact that it was a rougher substrate has contributed to a better wetting of the surface as it will be discussed shortly.

The porous network of the paper coatings have not been evaluated in this study, the technique used for this purpose is usually mercury porosimetry together with software simulations. We would like to refer the reader to the extensive work from Gane et al., ${ }^{\mathbf{4 9}}$ Ridgway et al. ${ }^{50,51}$ and co-authors in this subject.

Surface energy of the substrates. The surface energy parameters of the liquids used to perform the contact angle measurements are described in Table 2 and the contact angle data are described in Table 3.

$$
\gamma_{\mathrm{L}}(1+\cos \theta)=2\left[\left(\gamma_{\mathrm{S}}^{\mathrm{LW}} \gamma_{\mathrm{L}}^{\mathrm{LW}}\right)+\left(\gamma_{\mathrm{S}}{ }^{+} \gamma_{\mathrm{L}}{ }^{-}\right)+\left(\gamma_{\mathrm{S}}{ }^{-} \gamma_{\mathrm{L}}{ }^{+}\right)\right]^{1 / 2}
$$

where $\theta=$ contact angle, $\gamma_{\mathrm{L}}=$ overall surface tension of the liquid, $\gamma_{\mathrm{S}}=$ overall surface energy of the solid, $\gamma_{\mathrm{L}}^{\mathrm{LW}}=$ dispersive component of the surface tension of the liquid, $\gamma_{\mathrm{S}}^{\mathrm{LW}}=$ dispersive component of the surface energy of the solid, ${\gamma_{\mathrm{L}}}^{+}=$the acid component of the surface tension of the liquid, $\gamma_{\mathrm{L}}{ }^{-}=$the base component of the surface tension of the liquid, $\gamma_{\mathrm{S}}{ }^{+}=$the acid component of the surface energy of the solid, $\gamma_{\mathrm{S}}{ }^{-}=$the base component of the surface energy of the solid.

Busscher et $a l .{ }^{54}$ report a polar component for the surface energy of diiodomethane (methylene iodide) (i.e.; $\gamma_{\mathrm{L}}^{\mathrm{LW}}=47.4$ $\mathrm{mN} \mathrm{m}{ }^{-1}$ and $\gamma_{\mathrm{L}}^{\mathrm{AB}}=2.6 \mathrm{mN} \mathrm{m}^{-1}$ ) we noticed this after performing our measurements. $\alpha$-Bromonaphthalene is a liquid with only dispersive components and could be used instead for better accuracy. The overall surface energy $\left(\gamma_{\mathrm{s}}\right)$ is a sum of the dispersive $\left(\gamma_{\mathrm{S}}^{\mathrm{LW}}\right)$ and the polar component $\left(\gamma_{\mathrm{S}}^{\mathrm{AB}}\right)$ of the surface energy. We also wish to point out that the ambient temperature during the experiment influence the contact angle and that the higher the temperature the lower the surface tension. The values described in Table 2 are at $20^{\circ} \mathrm{C}$ and would be lower at the temperature of $23{ }^{\circ} \mathrm{C}$, the ambient temperature where the measurements were carried out.

The resulting surface energy data are listed in Table 4 . They were obtained from the instrument software that used eqn (2) to determine the parameters of the surface energy of the substrates. All substrates show a strong electron donor $\gamma_{\mathrm{s}}{ }^{-}$ (Lewis base) and a negligible electron acceptor $\gamma_{\mathrm{S}}{ }^{+}$(Lewis acid) indicating a very asymmetric polarity characteristic to monopolar surfaces, according to Van Oss. ${ }^{52}$ Due to the polar component of the surface energy (i.e., $\gamma^{\mathrm{AB}}=18 \mathrm{mN} \mathrm{m}^{-1}$ ) being slightly higher than the other substrates, the substrate $\mathrm{S} 1$ is more favorable to wetting of a polar ink than the other substrates; as a result we observed a lower contact angle measured for the ink on this substrate $35.6^{\circ}$ compared to the others (see Table 3 ).

Surface roughness. We evaluated the surface roughness of the substrates through AFM scanning of an area of $50 \mu \mathrm{m}^{2} . S_{\mathrm{q}}$ is the root mean square roughness (RMS) that is the average of 
Table 2 Lifshitz-van der Waals components and electron-donor parameters for the liquids used for the surface energy estimation of the substrates 52,53

\begin{tabular}{|c|c|c|c|c|c|}
\hline Liquid & $\gamma_{\mathrm{L}}\left[\mathrm{mN} \mathrm{m}^{-1}\right]$ & $\gamma_{\mathrm{L}}^{\mathrm{LW}}\left[\mathrm{mN} \mathrm{m}^{-1}\right]$ & $\gamma_{\mathrm{L}}^{\mathrm{AB}}\left[\mathrm{mN} \mathrm{m}^{-1}\right]$ & $\gamma_{\mathrm{L}}^{+}\left[\mathrm{mN} \mathrm{m}^{-1}\right]$ & $\gamma_{\mathrm{L}}^{-}\left[\mathrm{mN} \mathrm{m}^{-1}\right]$ \\
\hline Water & 72.8 & 21.8 & 51 & 25.5 & 25.5 \\
\hline Diiodomethane & 50.8 & 50.8 & 0 & 0 & 0 \\
\hline
\end{tabular}

Table 3 Contact angle data measured with four different liquids: diiodomethane, ethylene glycol, water and the ink PEDOT:PSS. Each measurement was repeated 5 times, and the average error for the measurements was $\pm 2^{\circ}$

\begin{tabular}{lllll}
\hline Substrate & Diiodomethane & Ethylene glycol & Water & Ink \\
\hline S1 & $19.7^{\circ}$ & $20.1^{\circ}$ & $19.7^{\circ}$ & $35.6^{\circ}$ \\
S2 & $31.5^{\circ}$ & $34.7^{\circ}$ & $38.8^{\circ}$ & $50.1^{\circ}$ \\
S3 & $23.8^{\circ}$ & $28.1^{\circ}$ & $43.0^{\circ}$ & $56.4^{\circ}$ \\
S4 & $23.4^{\circ}$ & $23.3^{\circ}$ & $37.3^{\circ}$ & $47.3^{\circ}$ \\
S5 & $23.8^{\circ}$ & $33.1^{\circ}$ & $40.1^{\circ}$ & $51.0^{\circ}$ \\
S6 & $33.1^{\circ}$ & $37.0^{\circ}$ & $46.0^{\circ}$ & $43.4^{\circ}$
\end{tabular}

height deviations taken from the mean image data plane. Note that the surface roughness value for $\mathrm{S} 1$ (i.e., $S_{\mathrm{q}}=105 \mathrm{~nm}$ ) is 10fold higher than for the other substrates, the resin-coated substrates we tested were all in the same range of roughness (i.e., $\approx 10 \mathrm{~nm}$ ) (see Fig. 8). In the paper industry standards, RMS roughness in the range of $100 \mathrm{~nm}$ is considered smooth. ${ }^{55} \mathrm{In}$ this way, the substrate S1 may also be considered smooth. It is an engineering technique to add the PE layer to inkjet papers to reduce the roughness, ${ }^{31}$ but this increases complexity in production, leading to higher costs and making it more difficult to recycle.

There are basically two wetting regimes for rough substrates: homogeneous and heterogeneous. ${ }^{56}$ The difference between them is that in the first the liquid fill the roughness grooves and in the second air would fill the grooves. For homogeneous wetting regimes the Wenzel equation apply as for the second, Cassie-Baxter apply. ${ }^{56}$ Wetting is enhanced by roughness for homogeneous regimes according to the Wenzel equation if the contact angle is smaller than $90^{\circ}$ and hampered if the contact angle is higher than this value. ${ }^{57}$

Samyn et al. ${ }^{36}$ also pointed out in their studies that for an intrinsically hydrophilic material, the wetting will be amplified the higher the number of asperity sites. We observe this effect for S1, a rougher substrate compared to the others with significantly better wetting performance.

The roughness of the substrate may also influence the result of the contact angle measurement as it does the drop volume of the test liquid and the time required for the drop to stabilize in the surface. ${ }^{58}$ From a study presented by Busscher et al. ${ }^{54}$ if the surface roughness is below $100 \mathrm{~nm}$ it does not impact the contact angle result. The substrates analyzed in this study have surface roughness below this value except $\mathrm{S} 1$ (i.e.; $105 \mathrm{~nm}$ ) but with a value very close to this threshold. For this reason we did not consider the Wenzel equation that take into account the surface roughness to correct the contact angle results as it was done by Ihalainen et al. ${ }^{31}$

\section{Part 2: PEDOT:PSS ink distribution on monopolar substrates and chemical interactions ink/substrate}

The analyses of the coating composition is important specially when we wish to verify the inertness of the substrates. Chemical reactions between the substrate IRL and the printed ink layer would appear in the analyses of the FTIR illustrated in Fig. 9. These spectra were acquired from the surface of a $20 \mathrm{pxl}$ printed line with 3 printed layers (PLs) of the ink and from the surface of the substrate without the printed lines. From these data we can evaluate the inertness of the substrates to the PEDOT:PSS ink, as there is no indication of a chemical reaction verified by the fact that the spectra for the ink are similar in all substrates. Note that the region for the fingerprint of the PEDOT:PSS is in the range of $900 \mathrm{~cm}^{-1}$ to $1700 \mathrm{~cm}^{-1}$ similar to what is presented for the Raman in Fig. 10A. The PEDOT:PSS chemical structure is presented in Fig. 10B.

In Fig. 10A the spectra of the printed PEDOT:PSS ink on each substrate are illustrated. Note that the curves in Fig. 10A were normalized to the highest intensity of the oxyethylene ring deformation band at the vibration frequency $991 \mathrm{~cm}^{-1}$, and all spectra were smoothed at 1 degree. The other vibration modes

Table 4 Surface energy components and parameters for the substrates obtained by solving eqn (2) and using the contact angle measurement data from Table 3

\begin{tabular}{|c|c|c|c|c|c|}
\hline Substrate & $\gamma_{\mathrm{s}}\left[\mathrm{mN} \mathrm{m}^{-1}\right]$ & $\gamma_{\mathrm{S}}^{\mathrm{LW}}\left[\mathrm{mN} \mathrm{m}^{-1}\right]$ & $\gamma_{\mathrm{S}}^{\mathrm{AB}}\left[\mathrm{mN} \mathrm{m}^{-1}\right]$ & $\gamma_{\mathrm{s}}^{+}\left[\mathrm{mN} \mathrm{m}^{-1}\right]$ & $\gamma_{\mathrm{S}}^{-}\left[\mathrm{mN} \mathrm{m}^{-1}\right]$ \\
\hline S1 & 65.8 & 47.9 & 18.0 & 1.1 & 74.5 \\
\hline S2 & 57.7 & 43.6 & 14.1 & 0.9 & 58.4 \\
\hline S4 & 55.3 & 46.7 & 8.6 & 0.3 & 52.1 \\
\hline S5 & 61.3 & 46.6 & 14.8 & 1.0 & 54.9 \\
\hline S6 & 53.1 & 42.9 & 10.1 & 0.5 & 47.6 \\
\hline
\end{tabular}



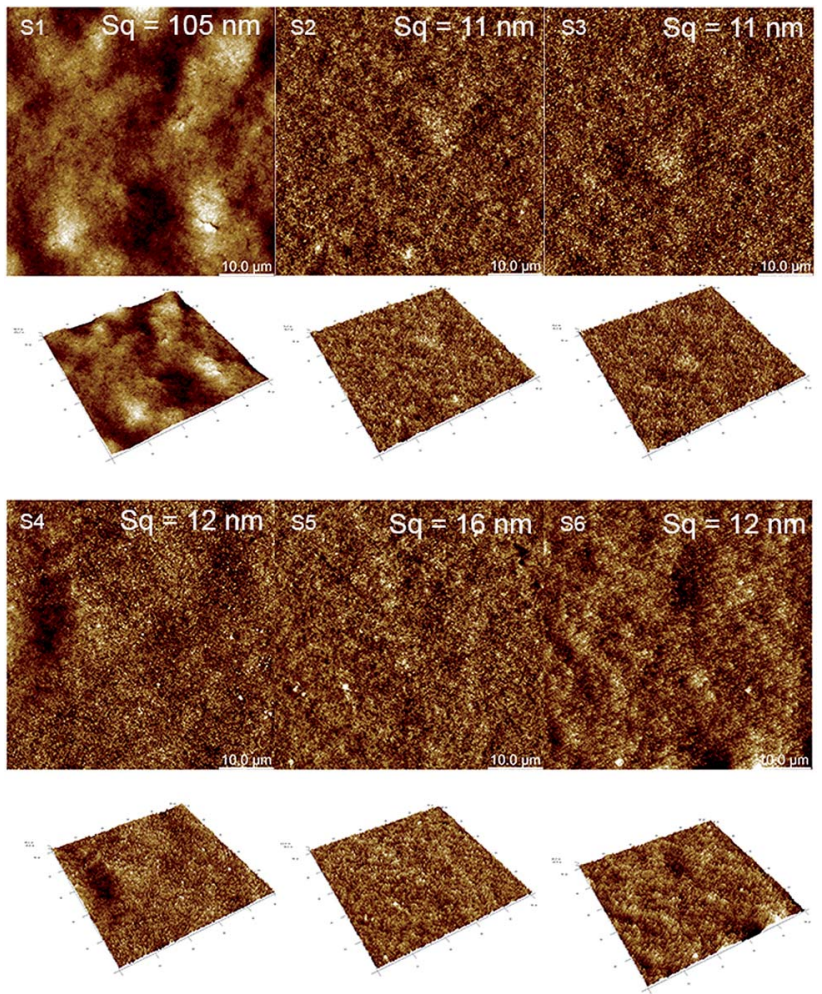

Fig. 8 RMS surface roughness analyses of the substrates accessed by AFM. The legend indicate $10 \mu \mathrm{m}$.

observed were at the highest intensity band at the frequency $1433 \mathrm{~cm}^{-1}$ and correspond to symmetric stretching $\left(\mathrm{C}_{\alpha}=\mathrm{C}_{\beta}\right)$, asymmetric stretching $(\mathrm{C}=\mathrm{C}-\mathrm{O})$ at $1504 \mathrm{~cm}^{-1}, \mathrm{C}_{\beta}-\mathrm{C}_{\beta}$ stretching at $1368 \mathrm{~cm}^{-1}$ and asymmetric inter-ring stretching $\left(\mathrm{C}_{\alpha}-\mathrm{C}_{\alpha}\right)^{59}$ at $1252 \mathrm{~cm}^{-1}$ indicating that there was no change in the structure of PEDOT in the ink/substrate interface. Due to the fluorescence during measurement of the substrate using Raman we also present the spectra acquired using FTIR in Fig. 9.

When the laser is distant from the focus point, a larger area will be excited by the laser beam which will impact the measurement because the signal being measured will account for the gains of a larger illuminated volume and the losses due to the surface not being in focus. ${ }^{60}$ It is the optical system that will dictate how much of the signal that is not in focus will be detected.

In Fig. 10C, the position of the laser was set to be $30 \mu \mathrm{m}$ above and below the focus point and we plotted the data for the 5 spectra at the maximum intensities below the focus point. The loss of intensity of the laser is expressed in percentage of the signal compared to the maximum measured intensity. The maximum intensity that we evaluated was for the band correspondent to the asymmetric stretching $(\mathrm{C}=\mathrm{C}-\mathrm{O})$ at $1504 \mathrm{~cm}^{-1}$ and the area within the frequency $1379-1482 \mathrm{~cm}^{-1}$ corresponding to the width of this band. The software from the instrument consider the data above the focus point negative values, these measurements are equivalent to the laser moving away from the sample. Analogous to that, the positive data would be the data below the focus point, the measurement into

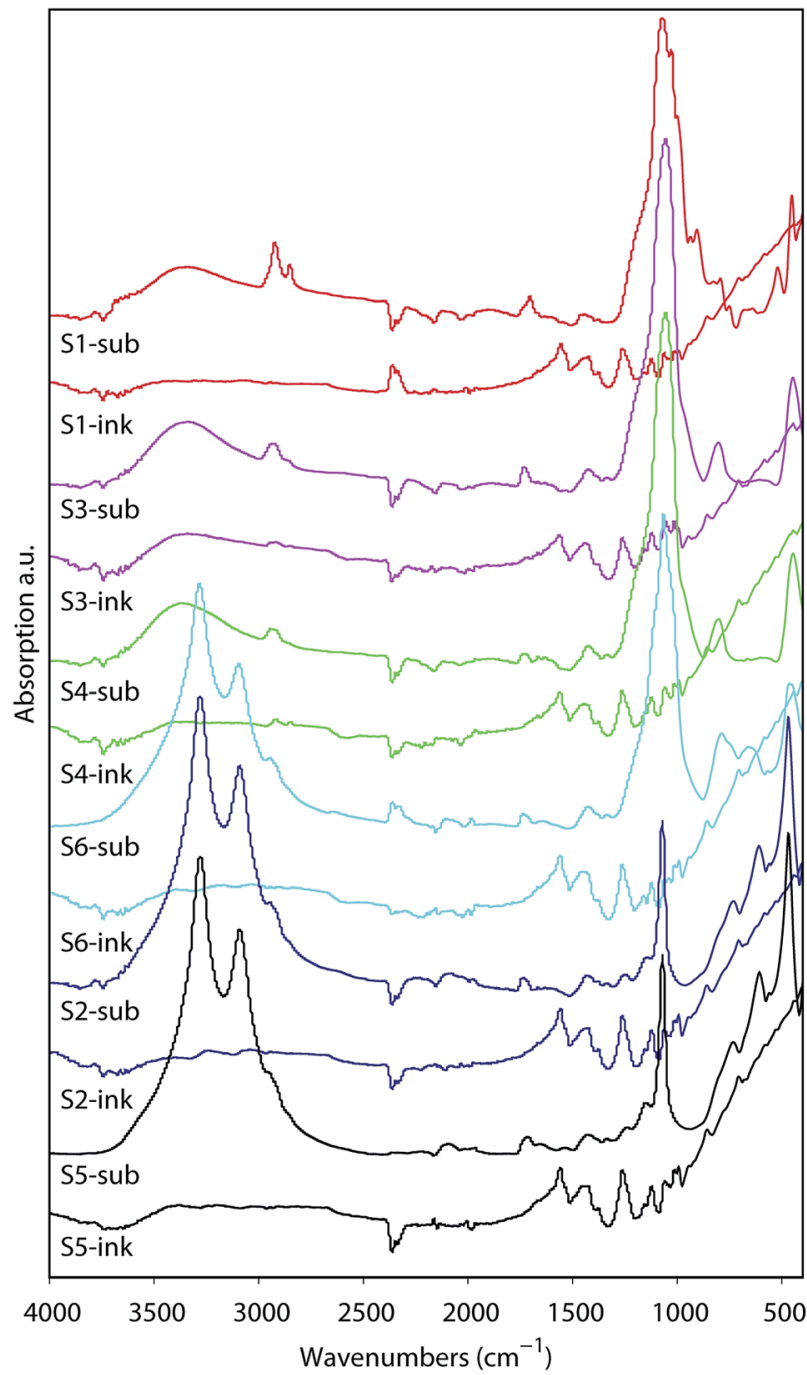

Fig. 9 FTIR for the substrate and the printed PEDOT:PSS ink layer. The measurement for the ink was done on the surface of a 20 pxl printed line with 3 PLs of the ink while the spectra for the substrate was acquired on the surface of the substrate. Sx-sub indicate the spectra for the respective substrate where $x$ is the number of the substrate from 1 to 6 . Sx-ink indicate the spectra of the printed ink on the respective substrate.

the sample in depth (YZ-direction). This loss in intensity could also be due to the differences in refractive index, the reduction of the ink volume and etc. Our aim is to evaluate if there would be a change in the spectra in $Y Z$ direction characterizing chemical reactions but we did not observe changes in the spectra besides the loss of intensity meaning that the substrates remain inert when the ink penetrate the IRLs of the substrates.

Ink distribution and de-wetting. To evaluate the ink distribution on the surface we also took into consideration the measurement for the $Y Z$ depth penetration. We mentioned earlier that there is a loss in the signal when the laser is moving away from the sample. But when we plot the maximum intensity of the laser at each position of the laser moving away from the surface and penetrating into the surface we found a curiosity that the results were not the same for the substrate $\mathrm{S} 1$ compared 

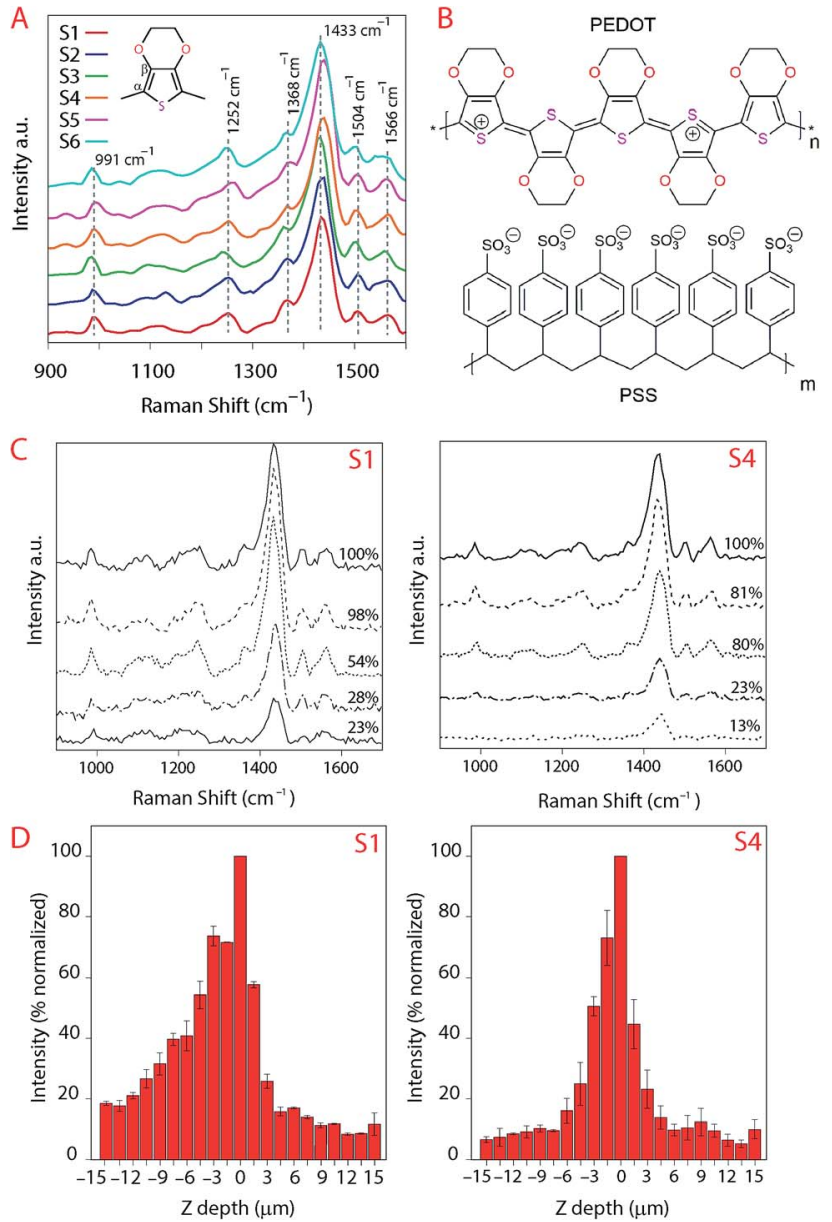

Fig. 10 (A) Raman spectra of the printed PEDOT:PSS ink onto the substrates indicating the vibration frequency of the characteristic bands that is the symmetric stretch at $1433 \mathrm{~cm}^{-1}\left(C_{\alpha}=C_{\beta}\right)$ and the asymmetric stretch $(C=C-O)$ at $1504 \mathrm{~cm}^{-1}$. These curves have been normalized at the $991 \mathrm{~cm}^{-1}$ band. (B) Chemical structure of PEDOT:PSS. (C) Raman YZ laser penetration analyses for S1 and S4 indicating the 5 spectra with the highest intensity from the focus point. This curves were not normalized. (D) Raman $Y Z$ profile of printed PEDOT:PSS ink ranging from $15 \mu \mathrm{m}$ above and below the focus point. The negative values indicate the position in the $Y Z$ direction above the focus, zero indicates the position of the focus point and the positive ones below focus. We evaluated the band at $1504 \mathrm{~cm}^{-1}$ and the area within the frequency $1379-1482 \mathrm{~cm}^{-1}$ corresponding to the width of this band. to the resin-coated samples. We present the data just for S4 because they were all similar for the other substrates (see Fig. S2 in the ESI $\uparrow$ for the Raman data on the other substrates). For the measurement, the position of the laser was set to be $30 \mu \mathrm{m}$ above and below the focus point. We plot the normalized Raman signal intensity $15 \mu \mathrm{m}$ above and below the focus point versus the laser penetration depth in micrometers in Fig. 10D with the error estimated based on three measurements.

The results show a higher intensity of the signal for the ink above the surface of S1 even at lower laser intensities (more distant from the surface) which we attribute to the ink density on top of the substrate for S1 being higher compared to the other substrates. That may also explain the lower electronic resistance measured for this substrate.

Noticing that the ink density could be evaluated using Raman, we obtained surface mapping of the printed surface in the $X Y Z$ direction to evaluate the ink distribution on the substrates in $X Y$ direction. The de-wetting of the ink through the intensity of the Raman signal was also evaluated. The analyses were done with an increment of $1.5 \mu \mathrm{m}$ in a $500 \mu \mathrm{m}^{2}$ area (see Fig. 11). For the $X Y$ mapping, the image at the highest Raman intensity was selected as representative of the mapping at the focus point. The measurement was done in all directions $X Y Z$ with the increment equal to $1.5 \mu \mathrm{m}$. 4 data points in $Z$-direction were set to precisely reach the data at the highest intensity and then collected the mapping data in $X Y$ direction at that $Z$ position. The spectra were baseline corrected, and cosmic rays were removed. Red areas indicated stronger signals. Blue indicated no or negligible signal. The mapping can be compared with microscopy images of the same area in the same magnitude if we observe Fig. 12A for S1 and S3 we can make some correlations to the Raman mapping images, the image for S4 would be very similar to S3 (the other microscopy images are presented in the ESI Fig. S3†). Note that Fig. 11 does not present the printed lines in the printing direction as is the case in Fig. 12A. Please look at Fig. 11 in a vertical position for this comparison.

We observe areas with print roughness especially pronounced for S1 and sharp lines with slightly uneven ink distribution for S3. In Fig. 12B some pigments in the CL1 of S1 are not fully covered with one printing layer (PL) of the ink as they are for S3 for example this create an uneven distribution of the ink that we also observed in the surface mapping (i.e.,

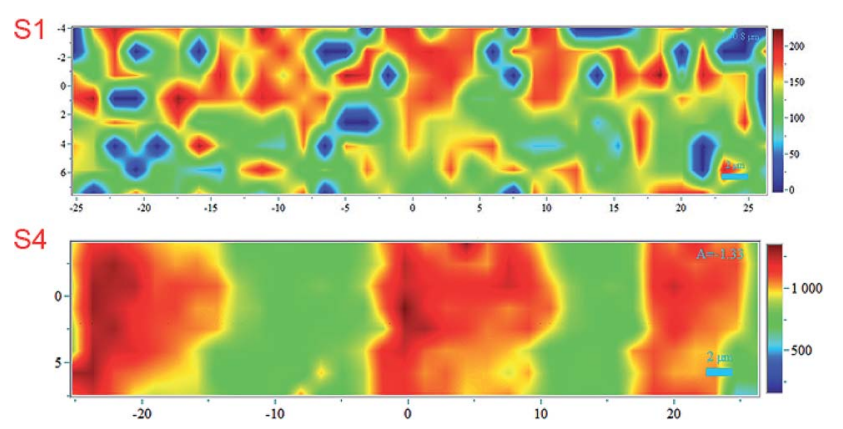

Fig. 11 Raman mapping of the printed surface of S1 and S4 substrates. The scale bar indicates the maximum and minimum intensities for the band at $1504 \mathrm{~cm}^{-1}$. 
Fig. 11). In Fig. 11 the anisotropic ink distribution between S1 and S4 are evident. We performed profilometry on a $20 \mathrm{pxl}$ printed line on S3, these results are presented in the ESI Fig. S6. $\dagger$

A
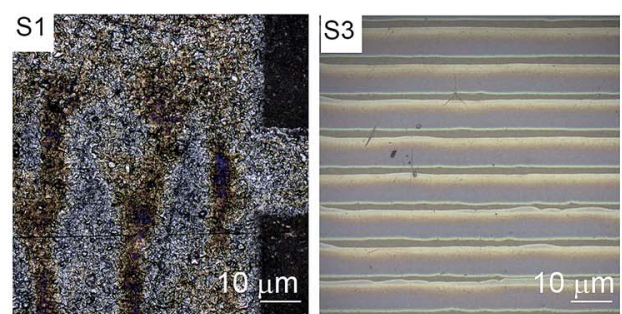

B
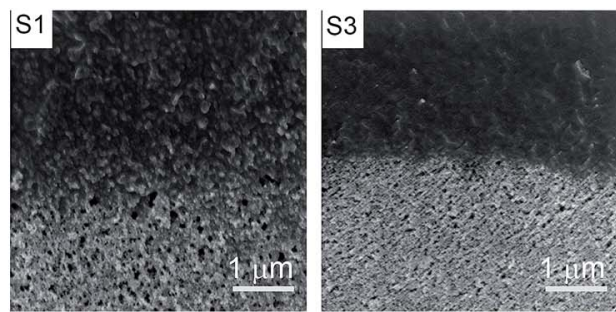

C
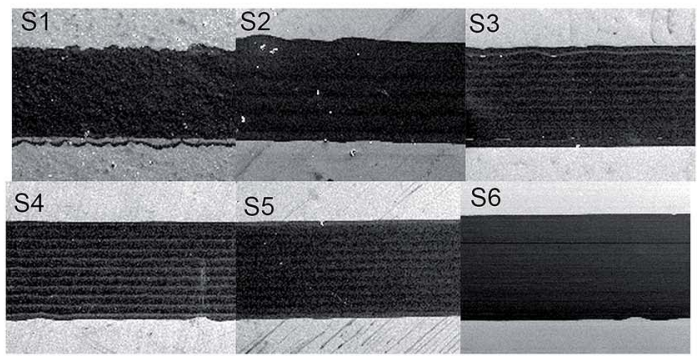

D

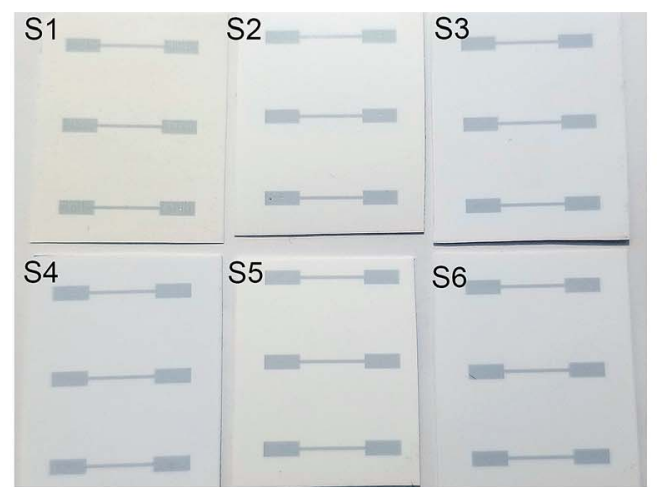

E

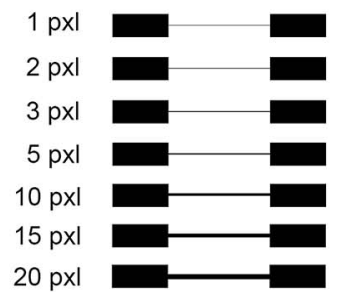

Fig. 12 (A) To the left, Raman microscopy images (5× magnification) of the printed surfaces of S1 and to the right, the printed surface of S3 (10 $\times$ magnification). (B) SEM images of the printed surfaces at the interface ink/substrate for substrates S1 and S3. Scale bar indicates 1 $\mu \mathrm{m}$. (C) Magnified SEM images of the printed surfaces of a $20 \mathrm{pxl}$ line with adjusted contrast. (D) Photograph of printed samples of $20 \mathrm{pxl}$ lines ( $9 \mathrm{~mm}$ length) and contacts ( $4 \mathrm{~mm}$ length). (E) Template of the printed lines showing the line width in pixels to the left.
The line quality of the printouts can be qualitatively evaluated from sections of the printed lines accessed by SEM illustrated in Fig. 12C. To the naked eye, the differences in printability are not evident as can be seen from the photographs of the print-outs in Fig. 12D. S1 present worse printing quality than the other substrates. With this, we would like to point out that a somewhat lower printing quality could be acceptable in exchange for better electronic properties and more sustainable substrates for printed electronics.

Although not in the scope of this study, authors have reported the modification of the surface of cellulose based substrates with hydrocarbons and fluorocarbon based resins that resulted in better electronic performance together with an improve in print resolution ${ }^{\mathbf{3 8 - 4 0 , 6 1}}$ and in this way circumvent the high absorbency of the substrates that resulted in poor printability.

\section{Part 3: electrical properties and applications}

The electrical resistance was measured for the printed lines ranging from 1 to $20 \mathrm{pxl}$, the thickness of this substrates is presented in Table 5. The template illustrated in Fig. 12E was used to print the patterns in a number of different substrates to evaluate the influence of the line thickness. In Table 5, we present the measured values of the line width of the $20 \mathrm{pxl}$ printed lines estimated using the SEM measurement tool.

Differently than reported in the literature for silver nanoparticles inks ${ }^{62}$ which showed higher resistance for silica containing coated substrates, we did not observe a significant influence of the coating composition on the electrical properties of the printed lines using the PEDOT:PSS ink. As from our results, the substrates were chemically inert to the ink.

The impact on the electrical properties of the number of printing passes and the sintering was also evaluated. Considering the 20 pxl lines (see Fig. 13A), we measured a 400-fold lower resistance than for a 1 pxl width line printed with $1 \mathrm{PL}$ (e.g., $0.11 \mathrm{M} \Omega$ and $38 \mathrm{M} \Omega$ respectively). Increasing the number of PLs reduce the resistance as can be seen from Fig. 13B and C. Comparing with the other substrates, the 20 pxl line printed in S1 show 100 fold lower resistance compared to the others (i.e, $0.11 \mathrm{M} \Omega$ for $\mathrm{S} 1$ and $\approx 13 \mathrm{M} \Omega$ for the other substrates with $1 \mathrm{PL}$ ). We attribute this to the higher roughness of substrate $\mathrm{S} 1$ (i.e., $105 \mathrm{~nm})$ compared to the other substrates $(\approx 10 \mathrm{~nm})$ which creates areas of different ink density.

The substrates were sintered for 30 minutes at $50{ }^{\circ} \mathrm{C}$ and $100{ }^{\circ} \mathrm{C}$ for each printed line illustrated in Fig. 13D, varying the

Table 5 Width of $20 \mathrm{pxl}$ printed lines. Values estimated from the SEM images using the measurement tool of the Tescan-MAIA3 software

\begin{tabular}{ll}
\hline Substrate & Width $[\mu \mathrm{m}]$ \\
\hline S1 & $418.7 \pm 21.7$ \\
S2 & $447.8 \pm 3.9$ \\
S3 & $450.5 \pm 5.8$ \\
S4 & $437.3 \pm 7.8$ \\
S5 & $451.7 \pm 5.7$ \\
S6 & $468.8 \pm 5.0$
\end{tabular}



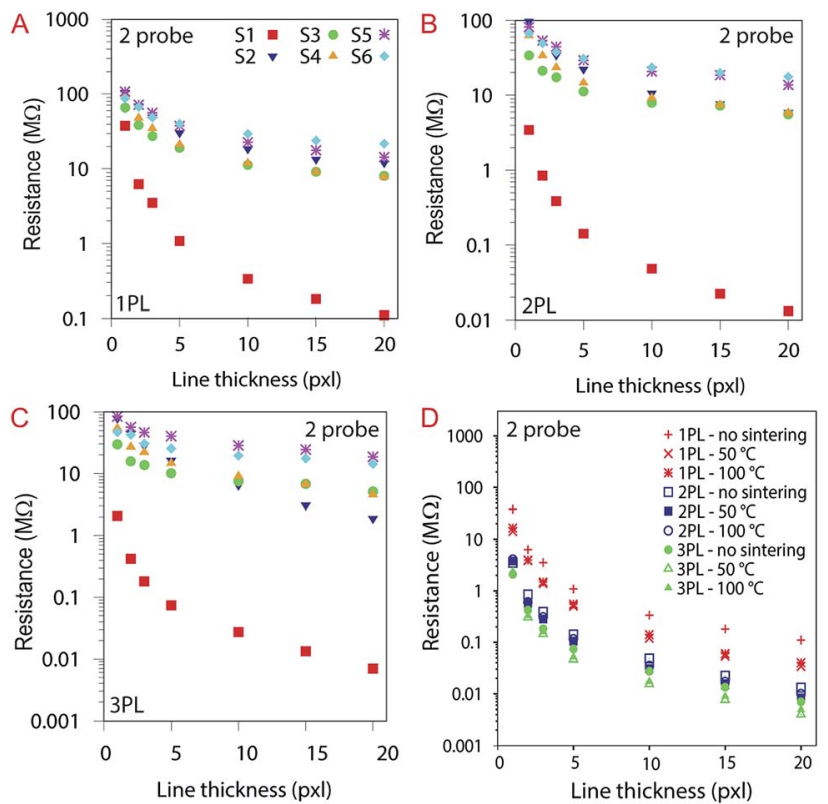

Fig. 13 (A), (B) and (C) Resistance of the printed lines from 1, 2, 3, 5, 10, 15 and 20 pxl width with 1, 2 and 3 PLs, respectively, without sintering, indicating the drop in resistance for the lines printed in S1. (D) The influence of sintering temperature in resistance for S1. For better understanding, the data here are divided into three groups i.e., red (1 $\mathrm{PL})$, green $(2 \mathrm{PL})$ and blue $(3 \mathrm{PL})$.

number of PLs. The influence of sintering temperature in resistance for S1: the higher the number of PL, the lower the resistance. For better understanding, the data here are divided into three groups (i.e., red (1 PL), green (2 PL) and blue (3 PL)). Sintering did not affect significantly the resistance for the other substrates (see ESI Fig. $\mathrm{S} 4 \dagger$ ).

The sheet resistance of the printed lines were evaluated using a 4-probe measurement setup. The contact resistance is attenuated with this measurement setup therefore the values measured for resistance are much lower. S1 still show a lower resistance compared to the other substrates with values around $59 \pm 0.2 \mathrm{k} \Omega$ $\mathrm{sq}^{-1}$ compared to an average of $550 \mathrm{k} \Omega \mathrm{sq}^{-1}$ for the other

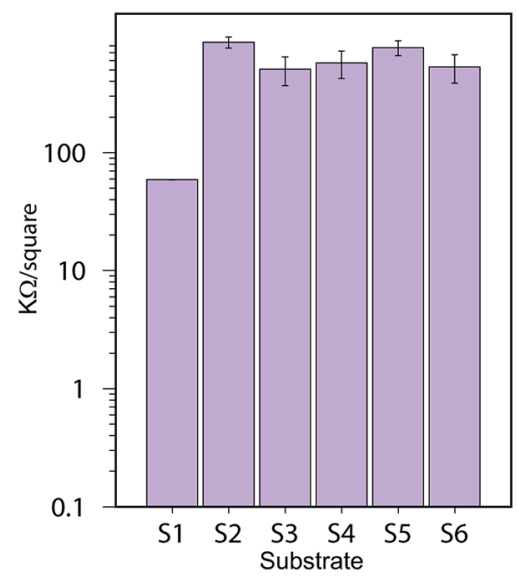

Fig. 14 Sheet resistance of a $20 \mathrm{pxl}$ printed line printed on the substrates S1 to S6. substrates. Substrate S2 and S5 that contain a $\mathrm{CL}$ of $\mathrm{AlO}(\mathrm{OH})$ show slightly higher resistance than the other resin-coated substrates. These results are illustrated in Fig. 14.

Comparison of sheet resistance of printed lines of PEDOT:PSS and graphene. We printed graphene lines using a commercially available ink on substrates S1 and S2. We could not measure the sheet resistance on sample S1 probably because of not enough contact between the nanosheets of graphene. In S2, on the other hand, we could measure the sheet resistance and the print quality was rather good. The samples were printed at 20 and $10 \mu \mathrm{m}$ drop spacing resolution. In the 10 $\mu \mathrm{m}$ the lines appear very glossy assembling a metallic surface. We observed that to achieve the same level of resistance for one printed layer of PEDOT:PSS in S2, we needed to print 20 PLs of the graphene ink with a resolution of $10 \mu \mathrm{m}$ drop spacing which increased the processing time of the printing considerably. The sheet resistance on the samples printed on $\mathrm{S} 2$ were $103 \pm 10 \mathrm{k} \Omega$ per square and $14 \pm 2 \mathrm{k} \Omega$ per square for 20 and $10 \mu \mathrm{m}$ drop spacing respectively for $20 \mathrm{pxl}$ lines and $174 \pm 1 \mathrm{k} \Omega$ per square and $55 \pm 5 \mathrm{k} \Omega$ per square for 15 pxl lines. These print outs are illustrated in Fig. S5 in the ESI. $\dagger$ Profilometry of the printed lines for PEDOT:PSS and graphene are also illustrated in the ESI (i.e., Fig. $\mathrm{S} 6$ and $\mathrm{S} 7 \dagger$ ).

Temperature sensor and thermoelectric generator applications. We would like to refer the reader to two other studies ${ }^{\mathbf{2 6 , 6 3}}$ that were performed in parallel to the present research where some of the substrates studied here were used to print a thermosensor ${ }^{63}$ and a triboelectric generator applications. ${ }^{26}$

\section{Conclusions}

A paper substrate without a PE surface layer showed comparably low electrical/resistance for printed PEDOT:PSS lines despite a RMS surface roughness of $105 \mathrm{~nm}$. The lack of the PE layer means that such water-based ink/substrate combinations could be recyclable. For all low roughness substrates investigated, pore size and surface energy were important characteristics. They influence de-wetting phenomena, and the final ink distribution. The Raman spectroscopy methodology was particularly successful in correlating ink distribution with printed line resistance.

\section{Conflicts of interest}

The authors declare no conflict of interest.

\section{Acknowledgements}

The Knowledge Foundation is acknowledged for funding. Viviane Forsberg also acknowledges ÅForsk Foundation (grant no. 18-281), J. Gust. Richert Foundation (grant no. 2018-00459), the Knut and Alice Wallenberg Foundation through the Wallenberg Wood Science Center and the Swedish Graphic Companies Federation for funding. The authors also acknowledge Ophelie Lancry (Horiba Scientific) and Magnus Hummelgård (Mid Sweden University) for valuable discussions about Raman spectroscopy and energy dispersive X-ray spectroscopy 
respectively. Vinay Kumar, Rajesh Koppolu and Martti Toivakka from Åbo Akademi are acknowledged for supplying the substrate S1. Henrik Andersson (Mid Sweden University) is acknowledged for supplying the substrates S2-S6 and for discussions about the inkjet printing part of this work. Tian Carey from Cambridge University is gratefully acknowledged for valuable contribution. Prof. Lars A. Berglund at KTH Royal Institute of Technology, Stockholm is gratefully acknowledged for fruitful discussions. Pavol Suly from Tomas Bata University is gratefully acknowledged for the help during the printing of the graphene lines presented in the ESI. This research has been supported by Treesearch.se.

\section{References}

1 H. Shirakawa, E. J. Louis, A. G. MacDiarmid, C. K. Chiang and A. J. Heeger, J. Chem. Soc., Chem. Commun., 1977, 578580.

2 A. G. MacDiarmid, Angew. Chem., Int. Ed., 2001, 40, 25812590.

3 H. Shirakawa, A. McDiarmid and A. Heeger, Chem. Commun., 2003, 2003, 1-4.

4 C. Wang, H. Dong, W. Hu, Y. Liu and D. Zhu, Chem. Rev., 2012, 112, 2208-2267.

5 M. Nikolka and H. Sirringhaus, in Conjugated Polymer-Based OFET Devices, ed. J. R. Reynolds, B. C. Thompso and T. A. Skotheim, CRC Press, 2019, ch. Conjugated Polymers: Properties, Processing, and Applications.

6 F. Jonas, W. Krafft and B. Muys, Macromolecular Symposia, 1995, pp. 169-173.

7 L. Groenendaal, F. Jonas, D. Freitag, H. Pielartzik and J. R. Reynolds, Adv. Mater., 2000, 12, 481-494.

8 N. Kim, I. Petsagkourakis, S. Chen, M. Berggren, X. Crispin, M. P. Jonsson and I. Zozoulenko, in Electric Transport Properties in PEDOT Thin Film, ed. J. R. Reynolds, B. C. Thompso and T. A. Skotheim, CRC Press, 2019, ch. Conjugated Polymers: Properties, Processing, and Applications.

9 M. Berggren and G. G. Malliaras, Science, 2019, 364, 233-234.

10 B. Winther-Jensen and K. West, Macromolecules, 2004, 37, 4538-4543.

11 H. Sirringhaus, T. Kawase, R. H. Friend, T. Shimoda, M. Inbasekaran, W. Wu and E. P. Woo, Science, 2000, 290, 2123-2126.

12 T. Carey, S. Cacovich, G. Divitini, J. Ren, A. Mansouri, J. M. Kim, C. Wang, C. Ducati, R. Sordan and F. Torrisi, Nat. Commun., 2017, 8, 1202.

13 A. G. Kelly, T. Hallam, C. Backes, A. Harvey, A. S. Esmaeily, I. Godwin, J. Coelho, V. Nicolosi, J. Lauth, A. Kulkarni, et al., Science, 2017, 356, 69-73.

14 F. Torrisi and T. Carey, Nano Today, 2018, 23, 73-96.

15 Y. H. Kim, C. Sachse, M. L. Machala, C. May, L. MüllerMeskamp and K. Leo, Adv. Funct. Mater., 2011, 21, 10761081.

16 L. Li, Y. Yu, G. J. Ye, Q. Ge, X. Ou, H. Wu, D. Feng, X. H. Chen and Y. Zhang, Nat. Nanotechnol., 2014, 9, 372.
17 M. Naguib, V. N. Mochalin, M. W. Barsoum and Y. Gogotsi, Adv. Mater., 2014, 26, 992-1005.

18 L. Niu, J. N. Coleman, H. Zhang, H. Shin, M. Chhowalla and Z. Zheng, Small, 2016, 12, 272-293.

19 S. Kim, A. Konar, W.-S. Hwang, J. H. Lee, J. Lee, J. Yang, C. Jung, H. Kim, J.-B. Yoo, J.-Y. Choi, et al., Nat. Commun., 2012, 3, 1011.

20 V. Forsberg, R. Zhang, J. Bäckström, C. Dahlström, B. Andres, M. Norgren, M. Andersson, M. Hummelgård and H. Olin, PLoS One, 2016, 11, e0154522.

21 Q. H. Wang, K. Kalantar-Zadeh, A. Kis, J. N. Coleman and M. S. Strano, Nat. Nanotechnol., 2012, 7(11), 699-712.

22 Y. Deng, Z. Luo, N. J. Conrad, H. Liu, Y. Gong, S. Najmaei, P. M. Ajayan, J. Lou, X. Xu and P. D. Ye, ACS Nano, 2014, 8, 8292-8299.

23 P. N. Nirmalraj, T. Lutz, S. Kumar, G. S. Duesberg and J. J. Boland, Nano Lett., 2011, 11, 16-22.

24 B. J. Worfolk, S. C. Andrews, S. Park, J. Reinspach, N. Liu, M. F. Toney, S. C. B. Mannsfeld and Z. Bao, Proc. Natl. Acad. Sci. U. S. A., 2015, 112, 14138-14143.

25 V. R. Feig, H. Tran and Z. Bao, ACS Cent. Sci., 2018, 4, 337348.

26 H. Andersson, P. Šuly, G. Thungström, M. Engholm, R. Zhang, J. Mašlík and H. Olin, Journal of Low Power Electronics and Applications, 2019, 9, 14.

27 W. Colglazier, Science, 2015, 349, 1048-1050.

28 M. Irimia-Vladu, Chem. Soc. Rev., 2014, 43, 588-610.

29 T. Mori and S. Priya, MRS Bull., 2018, 43, 176-180.

30 R. Martins, D. Gaspar, M. J. Mendes, L. Pereira, J. Martins, P. Bahubalindruni, P. Barquinha and E. Fortunato, Appl. Mater. Today, 2018, 12, 402-414.

31 P. Ihalainen, A. Määttänen, J. Järnström, D. Tobjörk, R. Österbacka and J. Peltonen, Ind. Eng. Chem. Res., 2012, 51, 6025-6036.

32 D. E. Bugner, in Handbook of imaging materials, ed. A. S. Diamond and D. S. Weiss, Marcel Dekker, 2nd edn, 2002, ch. Paper and films for ink jet printing, pp. 603-627.

33 J. Kettle, T. Lamminmäki and P. Gane, Surf. Coat. Technol., 2010, 204, 2103-2109.

34 J. Schoelkopf, C. J. Ridgway, P. A. Gane, G. P. Matthews and D. C. Spielmann, J. Colloid Interface Sci., 2000, 227, 119-131. 35 C. J. Ridgway and P. A. Gane, Nord. Pulp Pap. Res. J., 2002, 17, 119-129.

36 P. Samyn, J. V. Erps, H. Thienpont and G. Schoukens, Appl. Surf. Sci., 2011, 257, 5613-5625.

37 J. Wang, Z. Zheng, H. Li, W. Huck and H. Sirringhaus, Nat. Mater., 2004, 3, 171.

38 Z. Gozutok, O. Kinj, I. Torun, A. T. Ozdemir and M. S. Onses, Cellulose, 2019, 26, 3503-3512.

39 J. Lessing, A. C. Glavan, S. B. Walker, C. Keplinger, J. A. Lewis and G. M. Whitesides, Adv. Mater., 2014, 26, 4677-4682.

40 A. C. Glavan, R. V. Martinez, A. B. Subramaniam, H. J. Yoon, R. M. D. Nunes, H. Lange, M. M. Thuo and G. M. Whitesides, Adv. Funct. Mater., 2014, 24, 60-70.

41 S. Shen, W. K. Ng, L. S. O. Chia, Y. Dong and R. B. H. Tan, Cryst. Growth Des., 2012, 12, 4987-4994.

42 S. Ram, Infrared Phys. Technol., 2001, 42, 547-560. 
43 P. Larkin, Infrared and Raman spectroscopy: principles and spectral interpretation, Elsevier, 2017.

44 B. Shokri, M. A. Firouzjah and S. Hosseini, Proceedings of 19th International Symposium on Plasma Chemistry Society, Bochum, Germany, 2009.

45 D. Wood and E. M. Rabinovich, Appl. Spectrosc., 1989, 43, 263-267.

46 G. L. Re, F. Lopresti, G. Petrucci and R. Scaffaro, Micron, 2015, 76, 37-45.

47 K. Holmberg, B. Jönsson, B. Kronberg and B. Lindman, Surfactants and polymers in aqueous solution, Wiley, 2003.

48 A. Hamraoui and T. Nylander, J. Colloid Interface Sci., 2002, 250, 415-421.

49 P. A. Gane, J. P. Kettle, G. P. Matthews and C. J. Ridgway, Ind. Eng. Chem. Res., 1996, 35, 1753-1764.

50 C. J. Ridgway, P. A. Gane and J. Schoelkopf, J. Colloid Interface Sci., 2002, 252, 373-382.

51 C. J. Ridgway and P. A. Gane, Colloids Surf., A, 2002, 206, 217239.

52 C. J. Van Oss, M. K. Chaudhury and R. J. Good, Chem. Rev., 1988, 88, 927-941.

53 W. Wu, R. J. Giese and C. Van Oss, Langmuir, 1995, 11, 379382 .
54 H. Busscher, A. van Pelt, P. de Boer, H. de Jong and J. Arends, Colloids Surf., 1984, 9, 319-331.

55 R. Bollström, A. Määttänen, D. Tobjörk, P. Ihalainen, N. Kaihovirta, R. Österbacka, J. Peltonen and M. Toivakka, Org. Electron., 2009, 10, 1020-1023.

56 A. Marmur, Langmuir, 2003, 19, 8343-8348.

57 A. Marmur, in The chemistry of inkjet inks, ed. S. Magdassi, World Scientific, 2010, ch. Equilibrium Wetting Fundamentals, pp. 43-53.

58 R. D. Deegan, O. Bakajin, T. F. Dupont, G. Huber, S. R. Nagel and T. A. Witten, Nature, 1997, 389, 827.

59 J. M. D'Arcy, M. F. El-Kady, P. P. Khine, L. Zhang, S. H. Lee, N. R. Davis, D. S. Liu, M. T. Yeung, S. Y. Kim, C. L. Turner, A. T. Lech, P. T. Hammond and R. B. Kaner, ACS Nano, 2014, 8, 1500-1510.

60 F. Adar, Spectroscopy, 2010.

61 Z. Tang, H. Li, D. W. Hess and V. Breedveld, Cellulose, 2016, 23, 1401-1413.

62 H. Andersson, A. Manuilskiy, C. Lidenmark, J. Gao, T. Öhlund, S. Forsberg, J. Örtegren, W. Schmidt and H.-E. Nilsson, Nanotechnology, 2013, 24, 455203.

63 J. Mašlík, H. Andersson, V. Forsberg, M. Engholm, R. Zhang and H. Olin, J. Instrum., 2018, 13, C12010. 